\title{
Challenges and Prospects of Nanopillar-Based Solar Cells
}

\author{
Zhiyong Fan ${ }^{1,2,3}$, Daniel J. Ruebusch ${ }^{1,2,3}$, Asghar A. Rathore ${ }^{1,2,3}$, Rehan Kapadia ${ }^{1,2,3}$, Onur Ergen ${ }^{1,2,3}$, Paul W. \\ Leu $^{1,2,3}$, and Ali Javey ${ }^{1,2,3}(\square)$ \\ ${ }^{1}$ Department of Electrical Engineering and Computer Sciences, University of California at Berkeley, Berkeley, CA 94720, USA \\ ${ }^{2}$ Berkeley Sensor and Actuator Center, University of California at Berkeley, Berkeley, CA 94720, USA \\ ${ }^{3}$ Materials Sciences Division, Lawrence Berkeley National Laboratory, Berkeley, CA 94720, USA \\ Received: 13 September 2009 / Revised: 26 September 2009 / Accepted: 26 September 2009 \\ CTsinghua University Press and Springer-Verlag 2009. This article is published with open access at Springerlink.com
}

\begin{abstract}
Materials and device architecture innovations are essential for further enhancing the performance of solar cells while potentially enabling their large-scale integration as a viable source of alternative energy. In this regard, tremendous research has been devoted in recent years with continuous progress in the field. In this article, we review the recent advancements in nanopillar-based photovoltaics while discussing the future challenges and prospects. Nanopillar arrays provide unique advantages over thin films in the areas of optical properties and carrier collection, arising from their three-dimensional geometry. The choice of the material system, however, is essential in order to gain the advantage of the large surface/interface area associated with nanopillars with the constraints different from those of the thin film devices.
\end{abstract}

\section{KEYWORDS}

Nanopillar-based photovoltaics, solar cells, nanowires (NWs)

\section{Introduction}

Semiconductor nanowires (NWs) exhibit unique electrical, optical, and mechanical properties arising from their miniaturized dimensions and single-crystalline structures with tunable atomic composition. In the past decade, they have been extensively investigated as the building blocks for various technological applications such as electronics [1-7], optoelectronics [8-10], and sensors [11-16]. Recently, as an emerging field, NWs have been utilized for energy harvesting devices, for instance, to convert thermal [17, 18], mechanical [19], and solar energy into electricity [20-33]. In this review article, we summarize the continuous progress of NW-based photovoltaics (PVs) while discussing the challenges and prospects associated with their integration for efficient and affordable solar cell modules.

\section{1) Device structures}

Various PV device structures based on vertically oriented NW (i.e., nanopillar) arrays can be envisioned as illustrated in Fig. 1, some of which have already been demonstrated experimentally. Specifically, three main device structures have been proposed and explored, including nanopillar (NPL) arrays with radial [21, 22] (Fig. 1(a)) and axial (Fig. 1(b)) junctions as well NPL arrays embedded in thin films

Address correspondence to ajavey@eecs.berkeley.edu 
of an absorber layer (Fig. 1(c)) [20, 28, 33]. Each of these device structures has its own advantages and disadvantages. The device structures utilizing radial NPL junctions (i.e., core/shell) or NPL collectors embedded in an absorber film provide significant enhancement of the junction area with reduced minority carrier collection lengths. On the other hand, the NPL axial and radial junctions provide a threedimensional (3-D) geometric configuration for reduced surface optical reflection and enhanced absorption. The enhanced carrier collection and optical absorption can in principle enable more efficient PVs as compared to planar structures. However, the surface and the interface area enhancement also result in an increase in surface/interface recombination events. In that

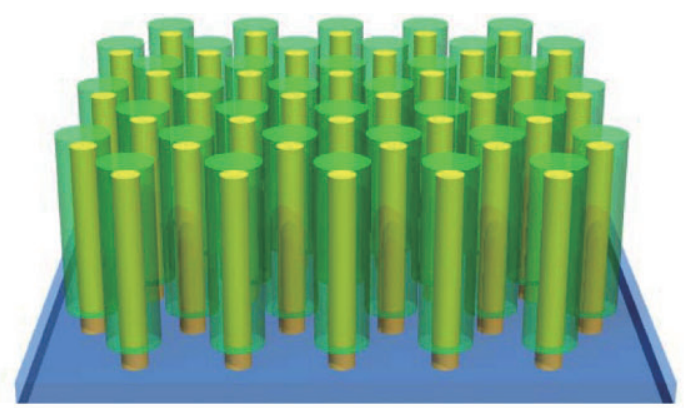

(a)

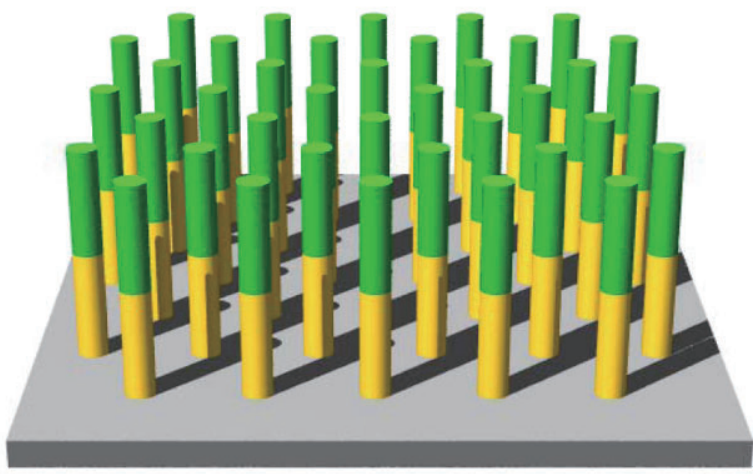

(b)

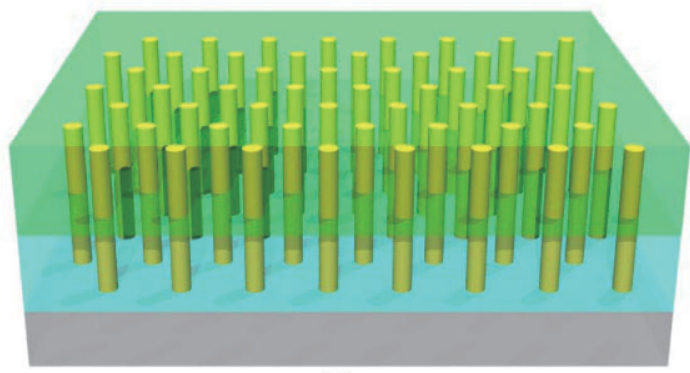

(c)

Figure 1 Nanopillar solar cell architectures. Three commonly explored PV device structures include: (a) NPL radial junctions; (b) NPL axial junctions; (c) NPL arrays embedded in thin film of an absorber regard, only material systems with low surface recombination velocities are desirable for the NPL configuration.

\section{2) Reduced optical reflection and enhanced absorption}

The efficiency of a PV cell depends on the probability of an incident photon being absorbed, and the subsequent collection of the generated carriers. Nanowire arrays can potentially provide a unique advantage due to their anti-reflective and light trapping properties. Silicon NW arrays of only several microns in length have been noted for their strong broadband optical absorption and dark visual appearance $[25,34]$. Numerical studies on the optical properties of disordered NW arrays by diffuse scattering [35] and ordered vertical arrays by specular reflection [36] have demonstrated that NW arrays have distinct absorption spectra from their thin film counterparts. The ordering of the NW arrays may be used as light trapping schemes analogous to random surface texturization or periodic grating couplers in thin films [37]. NW arrays can be used to redistribute the absorption spectrum from regions where absorption is not needed to spectral regions where absorption enhancement would lead to enhanced photocurrents.

The NW array material, diameter, length, and pitch can all be used to tailor the absorption spectrum of the NW solar cell. Parameters such as tapering of NWs may further improve upon the anti-reflective and enhanced absorption properties [36]. In our own studies, the exposure length of CdS NPL arrays out of anodic aluminum membranes was found to decrease the optical reflection as shown in Fig. 2 [20]. These various experimental and computational studies suggest that NPL arrays can be designed and optimized for PV cells by reducing the reflection and enhancing the optical absorption over specific spectral regions.

\section{3) Enhanced carrier collection efficiency}

NPL-based solar cells introduce important changes in the dynamics of carrier collection efficiency as compared to their thin film counterparts. Among other factors, high efficiency in traditional thin film 


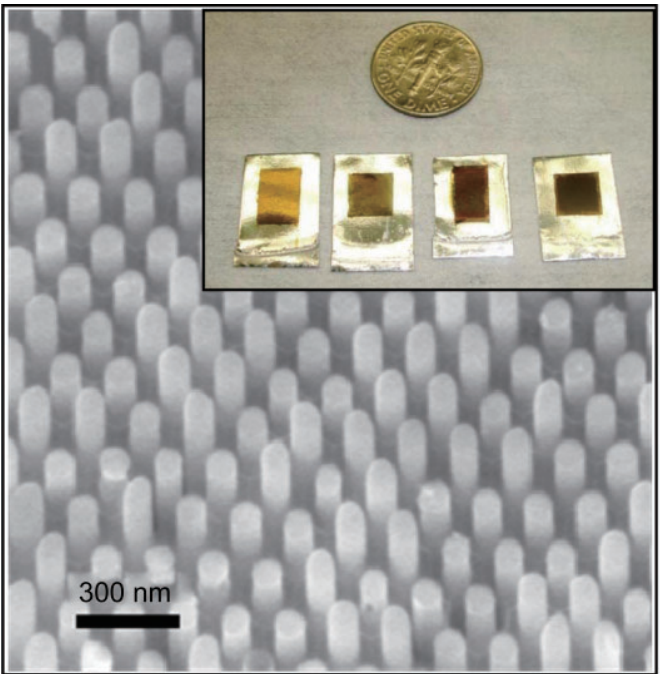

(a)

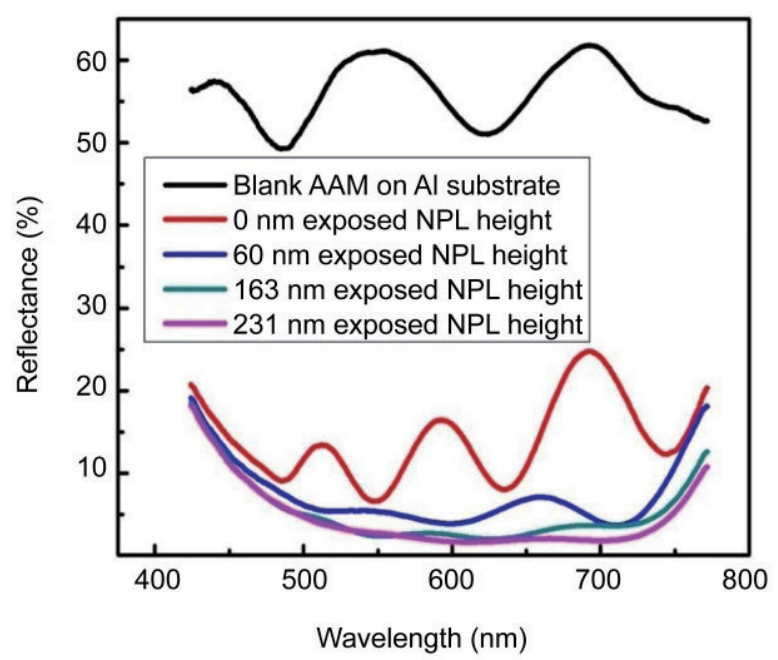

(b)

Figure 2 Optical reflectance studies of NPL arrays: (a) an SEM image of a CdS NPL array grown in an anodic alumina membrane. The membrane is partially etched to expose the tip of the NPLs. The inset is an optical image of four samples with increasing exposure height of $0 \mathrm{~nm}, 60 \mathrm{~nm}, 163 \mathrm{~nm}$, and $231 \mathrm{~nm}$ (left to right, respectively); (b) measured percentage reflectance versus wavelength of incident light for different NPL exposed heights. Reprinted with permission from Ref. [20] (Copyright 2009 Macmillan Publishers Ltd.)

solar cells requires efficient light absorption and carrier collection [38]. Yet, absorption and collection are in competition in thin film devices $[39,40]$. A thin film device must be thick enough for nearly all of the incident photons to be absorbed. Thus, ideally the thickness of the absorber film is tailored to the characteristic absorption length. However, the thickness of this film is also a critical dimension in efficient carrier collection. Minority carriers generated more than one diffusion length away from the $\mathrm{p}-\mathrm{n}$ junction space charge region have a vanishingly small probability of collection before being lost to recombination [39]. This constraint is of particular importance in thin film cells as they commonly contain a high density of recombination sites such as grain boundaries, vacancies, and impurities [40 -46]. Consequently, fabricating low cost films that simultaneously absorb photons and collect carriers efficiently is challenging. Many NPL solar cell architectures offer the advantage of orthogonalizing the light absorption and carrier collection processes [39]. For instance, NPLs can be integrated with photosensitive thin films or fabricated into radial $\mathrm{p}-\mathrm{n}$ junctions [21, 22, 24, 28-30, 47-50]. These architectures relieve the competition between photon absorption and carrier collection, and open the design space for further optimization [39]. Device thickness can be designed to account for the absorption length of the material while the NPL radial junctions can be optimized for minority diffusion lengths in the surrounding medium.

The performance benefit of orthogonalizing photon absorption and carrier collection directions is illustrated by the simulation of the CdS/CdTe system as shown in Fig. 3 [20]. In this work, the conversion efficiency of a device structure consisting of CdS NPL arrays embedded in a CdTe thin film (Fig. 3(a)) is compared to that of a planar CdS/CdTe cell (Fig. 3(b)). The simulations were performed primarily to obtain a qualitative comparison between the two solar cell geometries rather than a precise estimate of device performance. As such, both contacts were assumed to be optically transparent to incident photons and assumed to provide barrier-free and recombination-free conduction. Furthermore, the surface recombination processes were ignored in these preliminary simulation results. The simulated band gaps were $1.5 \mathrm{eV}$ and $2.4 \mathrm{eV}$ for $\mathrm{CdTe}$ and $\mathrm{CdS}$, respectively. Shockley-Read-Hall (SRH) was chosen to model the bulk recombination. Corresponding minority carrier lifetime used were $0.1 \mathrm{~ns}$ and $2.5 \mathrm{~ns}$ for CdTe and CdS, respectively. Minority carrier lifetime were assumed to be significantly lower in the polycrystalline CdTe film than in the single crystalline

\section{Springer}




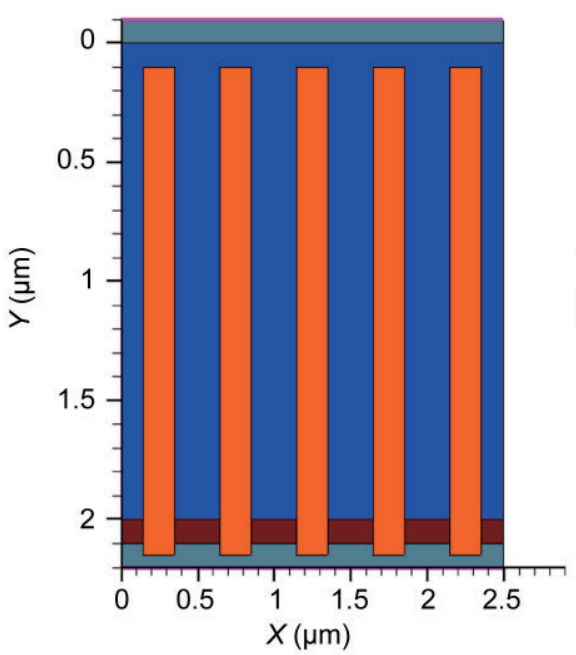

(a)

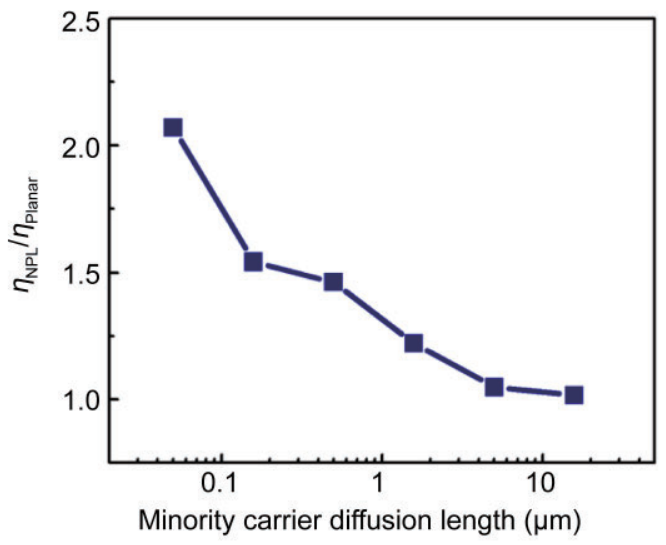

(c)

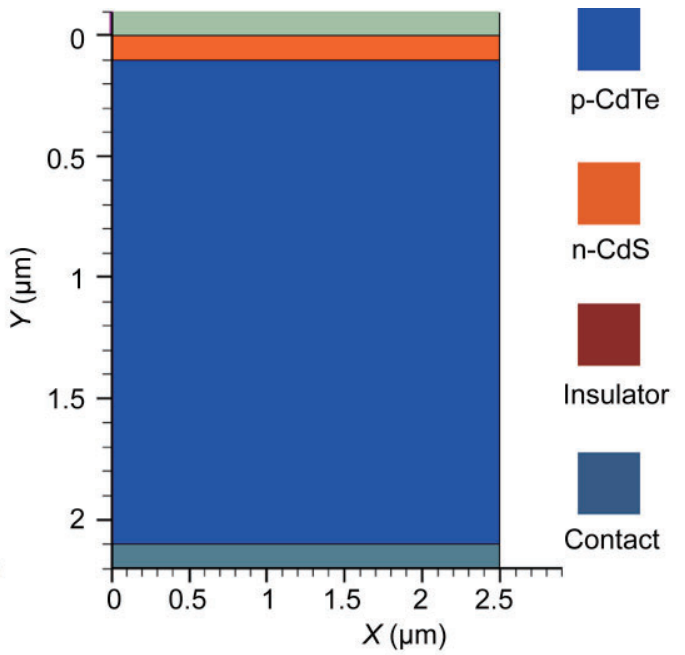

(b)

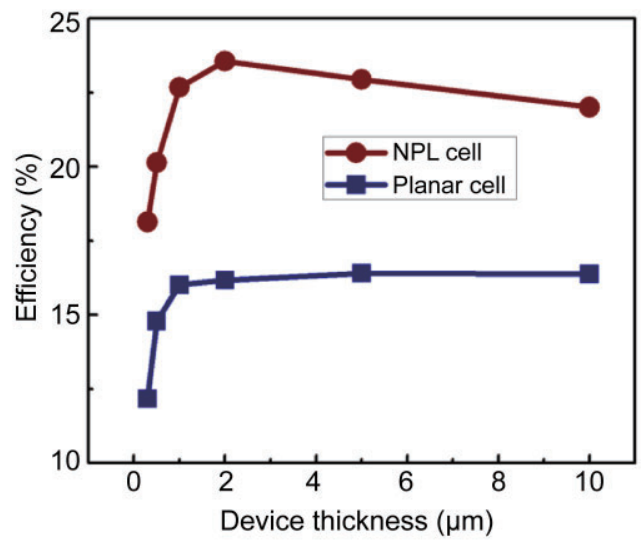

(d)

Figure 3 NPL device simulations: schematics of (a) CdS NPL/CdTe thin film and (b) CdS/CdTe planar thin film device structures used in the simulations; (c) ratio of the NPL to thin film efficiency versus bulk minority carrier diffusion length; (d) efficiency versus total device thickness for NPL and thin film cells. Reprinted with permission from Ref. [20] (Copyright 2009 Macmillan Publishers Ltd.)

CdS NWs. The CdTe thin film was simulated with electron and hole mobilities of $100 \mathrm{~cm}^{2} \cdot \mathrm{V}^{-1} \cdot \mathrm{s}^{-1}$ and $40 \mathrm{~cm}^{2} \cdot \mathrm{V}^{-1} \cdot \mathrm{s}^{-1}$. The CdS NPLs were assumed to have electron and hole mobilities of $100 \mathrm{~cm}^{2} \cdot \mathrm{V}^{-1} \cdot \mathrm{s}^{-1}$ and $25 \mathrm{~cm}^{2} \cdot \mathrm{V}^{-1} \cdot \mathrm{s}^{-1}$, respectively [20]. Carrier concentrations were assumed to be $1 \times 10^{16} \mathrm{~cm}^{-3}$ and $5 \times 10^{16} \mathrm{~cm}^{-3}$ for CdTe and CdS, respectively. Figure 3(c) shows a plot of the ratio between the efficiencies of the NPL and planar cells versus minority carrier diffusion length. All simulation parameters described above were used with the exception of varying carrier diffusion length. The device thickness for this simulation was fixed at $2.1 \mu \mathrm{m}$. The NW structure outperforms its thin film counterpart for small diffusion lengths. The importance of diffusion length in differentiating the performance of the simulated geometries is further emphasized as the ratio of efficiencies goes to 1 for diffusion lengths greater than the total device thickness. In Fig. 3(d), the extracted efficiencies for NPL and thin film devices are plotted versus the total device thickness with minority carrier diffusion length of $500 \mathrm{~nm}$ in CdTe. The NPL structure has a significant advantage in terms of conversion efficiency even when small material thicknesses are used.

\section{4) Choice of the material system}

The choice of the material system is particularly important for NW cell structures. Besides the need for an optimal band gap, the NW solar cell architecture requires the carrier loss to be dominated by bulk recombination processes as opposed to 
surface recombination [39]. The NW structure reduces the efficiency loss due to bulk recombination by shortening the required collection lengths. However, in doing so, the NW geometry introduces a significantly enhanced surface area. If surface recombination dominates, then the NW structure is detrimental to the overall device performance [39]. This requirement for efficient implementation of NW solar cell devices puts a premium on appropriate materials selection and surface treatment procedures to minimize the effect of surface and interface recombination. Surface recombination velocities reported for bulk silicon [51-53] and gallium arsenide [54, 55] substrates have exceeded $10^{6} \mathrm{~cm} \cdot \mathrm{s}^{-1}$ without the use of surface passivation layers, making these materials non-optimal for the NW solar cell configuration. On the other hand, II-VI semiconductors are notable for their relatively low untreated surface recombination velocities. For instance, typical surface recombination velocities reported for untreated CdS [56] and CdTe [57] thin films are $\sim 10^{3} \mathrm{~cm} \cdot \mathrm{s}^{-1}$ and $10^{4} \mathrm{~cm} \cdot \mathrm{s}^{-1}$, respectively. The lower surface recombination rates make these material systems attractive for NW solar cell applications. However, the effect of surface recombination on NW and NPL solar cell performance has not been experimentally studied. Such a study would further our understanding of the fundamental tradeoffs associated with the NW/NPL solar cell geometry.

Another constraint in the choice of the material system is the effect of impurities that are often associated with the NW growth process. The most common NW growth technique is the vapor-liquid -solid (VLS) method employing metal catalysts [47, 58-62]. While most of the metal catalyst remains at the tip of the NW during the growth and can be subsequently removed, a small fraction of the metal catalyst atoms diffuse into the material during the growth as has been previously observed experimentally $[63,64]$. Many metals form deep level trap states in semiconductor materials which significantly reduce minority carrier lifetime. These trap states act as efficient SRH recombination centers detrimental to carrier collection and overall device performance. For example, Au is a deep level trap in $\mathrm{Si}$, and yet it is among the most common catalyst materials used in Si NW growth [26]. Furthermore, carbon impurities that are often associated with the growth of NWs arising from organic surface monolayers (for instance, on the surface of the growth substrate or the catalytic metal colloids) can serve as deep level trap states [65]. In that regard, NW materials and catalysts must be chosen properly. Catalyst-free synthesis methods may also be used to further improve the minority carrier lifetime.

\section{Experimentally fabricated NW solar cells}

\subsection{Dye-sensitized NW solar cells}

A potential inexpensive alternative to the traditional solid-state PV cell is the relatively new dyesensitized cell (DSSC) technology. These photocells outperform current organic and hybrid organic -inorganic technology in terms of efficiency and stability [66, 67]. A typical DSSC consists of an anode substrate which is covered with a film of $\mathrm{TiO}_{2}$ or $\mathrm{ZnO}$ nanoparticles [67-70]. This results in a highly porous nanostructure film for a molecular sensitizer to covalently bond with. The incoming photons produce excitons that are immediately separated at the dye -particle interface so that the electrons diffuse into the film and the holes cause oxidation of electrolyte under the film [71]. Overall conversion efficiency is determined by a range of factors including the transmittance and conductivity of the substrate, the composition of the electrolyte, the type of sensitizer molecule, and the quality of the nanoparticle film [72 -77]. The disoriented polycrystalline topology of this cell results in trap-limited electron diffusion, which is a slow transport process that will significantly limit performance, especially at long wavelengths [78-82]. In order to increase the diffusion length of electrons, Law et al. suggested a structure in which the nanoparticle film is replaced with an array of vertically oriented single crystalline $\mathrm{ZnO}$ NWs. This structure is expected to provide a higher carrier collection efficiency than that of the nanoparticle aggregate [28].

To fabricate this structure, vertical arrays of $\mathrm{ZnO}$ NWs were grown by a seeded growth process on $\mathrm{F}: \mathrm{SnO}_{2}$ (FTO) substrates, as shown in Fig. 4(a). The electron diffusivity within the wires was estimated 
to be between $0.05-0.5 \mathrm{~cm}^{2} \cdot \mathrm{s}^{-1}$, much higher than that estimated for $\mathrm{ZnO}$ nanoparticle films. After bathing the NW arrays in the dye-sensitized electrolyte, the conductivity increased by up to $20 \%$, indicating that the diffusivity of the NWs was maintained in an operating environment. Devices with the highest surface area had characteristics of short circuit current, $J_{\mathrm{sc}}=5.3-5.85 \mathrm{~mA} \cdot \mathrm{cm}^{-2}$, open circuit voltage, $V_{\text {oc }}=0.61-0.71 \mathrm{~V}$, fill factor(FF), FF $=0.36-0.38$ and efficiency, $\eta=1.2 \%-1.5 \%$ as depicted in Figs. $4(\mathrm{~b})$ and 4(c). The highest external quantum efficiency of the cell measured (Fig. 4(b) inset) was $40 \%$ at $515 \mathrm{~nm}$ wavelength, corresponding to the maximum absorption of the dye. Enhanced electron transport is a product of the NW crystallinity and the internal electric field which assists in sweeping excited electrons from the electrolyte to the external circuit. An additional radial electric field caused by upward band bending on the NW surface further reduces the surface recombination velocity of the electrons. This allows for larger diffusion lengths. The effect of these macroscopic fields is to improve the overall electron transport by reducing the ambipolar diffusion which dominates the nanoparticle film devices.

The efficiency of the DSSC can be further improved by maximizing higher wavelength light conversion by increasing the length of the cell. However, a corresponding increase in electron diffusion length is needed. One of the simplest methods by which the electron diffusion lengths can be increased is through reducing the interfacial recombination rate by applying surface coatings on the nanocrystalline film [83-87]. In a separate study, $\mathrm{ZnO}-\mathrm{TiO}_{2}$ core-shell NWs were fabricated by Law et al. [88]. A conformal layer of $\mathrm{TiO}_{2}$ was deposited on $\mathrm{ZnO}$ NWs via an atomic layer deposition system. This oxide shell is expected to suppress recombination by incorporating an energy barrier that physically separates the photogenerated electrons from the oxidized species within the electrolyte. The layer also acts to passivate the recombination centers on the surface of the NWs. A smaller dark current provides evidence for the reduced recombination rate, and thus, increases the fill factor and open circuit voltage. It was reported that shells with 10-25 $\mathrm{nm}$ thickness produced substantial increase in open circuit voltage and fill

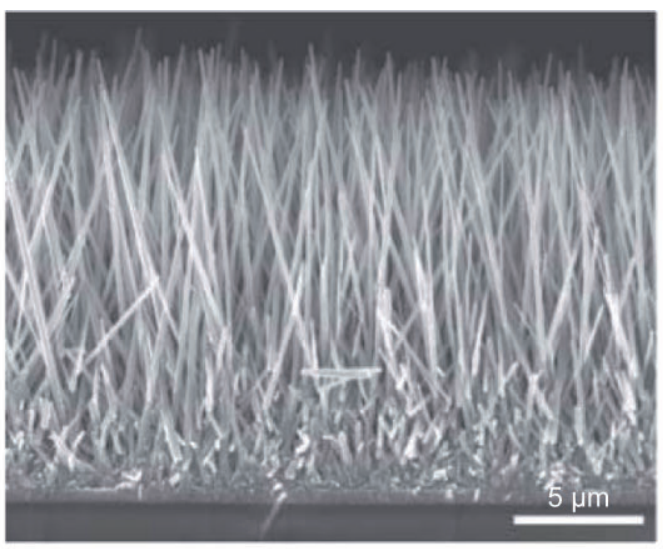

(a)

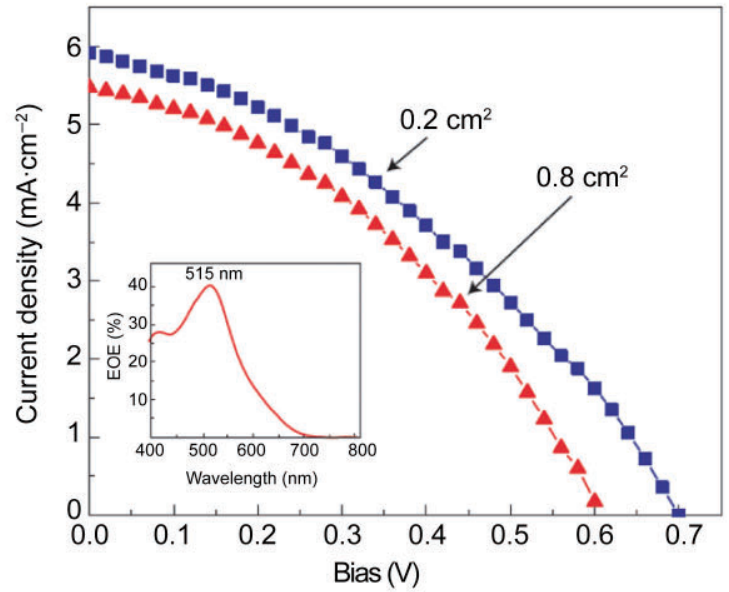

(b)

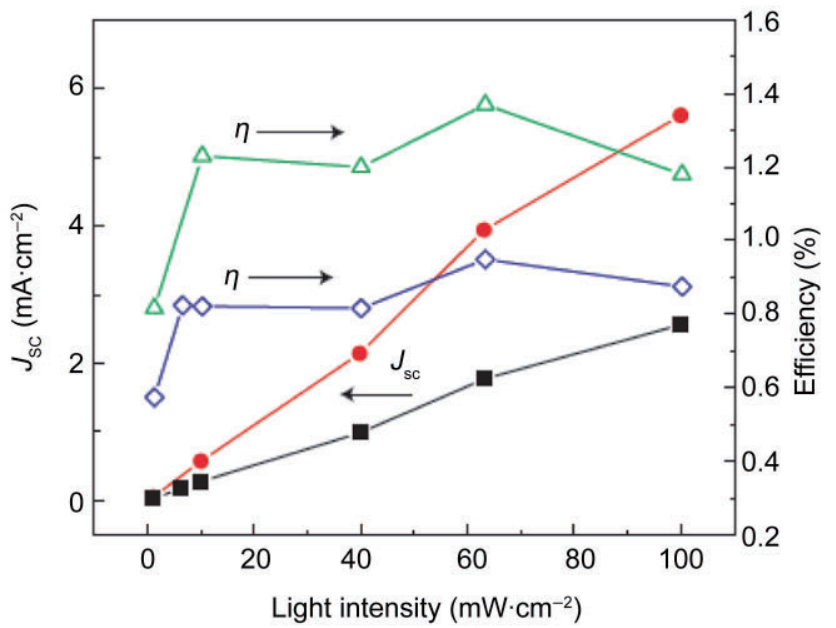

(c)

Figure 4 Dye-sensitized NW solar cells: (a) SEM cross-section of ZnO nanowires grown used in the dye-sensitized solar cell structure; (b) current density verses voltage curves for two cells of different active surface areas. Inset shows that maximum photo absorption of the dye occurs at $550 \mathrm{~nm}$, resulting in a $40 \%$ external quantum efficiency at that wavelength; (c) current density and efficiency plotted against light intensity shows that typical efficiency of the structure was measured to be $1.2 \%-1.5 \%$. Reprinted with permission from Ref. [28]. (Copyright 2005 Macmillan Publishers Ltd.) 
factor without decreasing the short-circuit current density. The results showed an overall conversion efficiency of $2.25 \%$, a significant improvement in performance of the cells.

While significant progress has been made in recent years in the advancement of DSSC technology, a main challenge is the degradation and lifetime of the organic component. In that regard, further studies and exploration are still needed to examine the viability of this hybrid technology. Additionally, while in principle NW-based DSSCs should enable higher efficiencies arising from their enhanced carrier transport properties, to date, the experimentally fabricated NW DSSCs are still inferior to the best nanoparticle DSSCs. In that regard, further device and materials exploration and optimization are needed to understand the performance limits of NW DSSCs.

\subsection{Si and GaAs NW solar cells}

While the aforementioned DSSC, employing an organic dye-inorganic NW hybrid structure, has generated interest, promising work has also been done on allinorganic NW solar cells. The majority of this work has focused on Si or GaAs NWbased devices. Tian et al. fabricated and characterized individual radial $\mathrm{p}-\mathrm{i}-\mathrm{n} \mathrm{Si}$ NW-structures, consisting of a p-type core with intrinsic and n-type shells [26], as shown in Fig. 5(a). One of the main advantages of a radial structure for PVs rests in shorter minority carrier collection lengths. $I-V$ curves for such devices were measured under an AM 1.5 G illumination. As shown in Fig. 5(b), values of $V_{\text {oc }} \sim 0.26 \mathrm{~V}$, $I_{\mathrm{sc}} \sim 0.503 \mathrm{nA}$, and $\mathrm{FF} \sim 0.55$ were measured. These values yield a device conversion efficiency $\eta \sim 3.4 \%$ after exclusion of the metal covered area. This conversion efficiency represents a significant improvement over other radial and axial junction devices reported previously based on single Si NWs.

Expanding upon the work on Si single NW solar cells, large area arrays of Si NPLs with radial $\mathrm{p}-\mathrm{n}$ junctions have been reported [22]. Garnett et al. have fabricated NW arrays consisting of an n-type crystalline silicon core and a p-type polycrystalline silicon shell [22]. A cross sectional scanning electron microscope (SEM) image of the fabricated NPL structure is shown in Fig. 5(c). The NPLs were formed on a Si wafer by an aqueous electroless etching method. A nanocrystalline p-type shell was deposited using a disilane source and boron trichloride dopant gas at $450{ }^{\circ} \mathrm{C}$, followed by a subsequent rapid thermal annealing at $1000{ }^{\circ} \mathrm{C}$ for $10 \mathrm{~s}$. After wet etching the backside silicon, the contacts were formed by
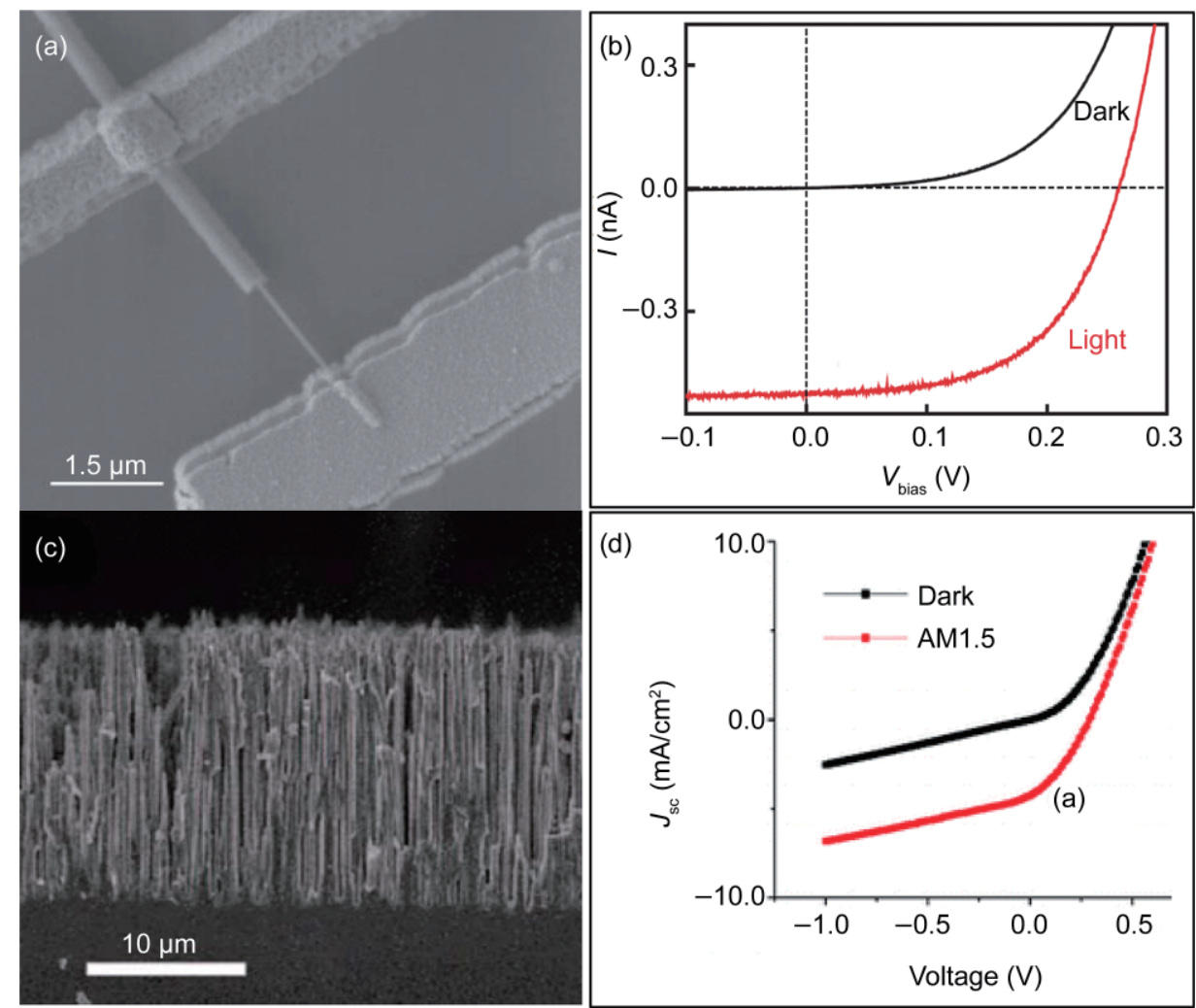

Figure 5 Radial Si NW photovoltaics: (a) SEM image of a single Si NW p-i-n device; (b) dark and light (AM 1.5 G) I-V curves for the $p-i-n$ NW device. Reprinted with permission from Ref. [26]. (Copyright 2007 Macmillan Publishers Ltd.); (c) SEM images of Si NPL arrays fabricated by aqueous electroless etching of a Si wafer. The NPLs consist of single crystalline ntype core and polycrystalline p-type shell; (d) $I-V$ curves of the enabled devices under dark and AM 1.5 G illumination. Reprinted with permission from Ref. [22]. (Copyright 2008 American Chemical Society) 
sputtering $\mathrm{Ti} / \mathrm{Ag}$ onto the $\mathrm{n}-\mathrm{Si}$ and $\mathrm{Ti} / \mathrm{Pd}$ onto the $\mathrm{p}$-Si. The fabrication resulted in vertically aligned and uniform $18 \mu \mathrm{m}$ long NWs with high packing density. The phosphorus dopant concentration in the $\mathrm{NW}$ cores is assumed to be unchanged from that of the initial Si wafer at $10^{16} \mathrm{~cm}^{-3}$. The fabricated solar cells were characterized under AM 1.5 G illumination to yield values of $V_{o c} \sim 0.29 \mathrm{~V}$ and $I_{s c} \sim 4.28 \mathrm{~mA} \cdot \mathrm{cm}^{-2}$ (Fig. 5(d)). The fill factor and overall efficiency were measured to be 0.33 and $0.46 \%$, respectively. Further improvements to this structure can be made through a reduction in NW surface recombination by passivating the surface and reducing surface roughness, as well as a reduction in series resistance by optimization of the contacts.

Although Si is the dominant material for conventional planar solar cells, it may not be the ideal material for NW solar cells primarily due to its low optical absorption coefficient and small band gap. Additionally, the relatively high surface recombination velocities and severe minority carrier lifetime degradation by $\mathrm{Au}$ and $\mathrm{C}$ impurities make Si nonideal for NW-based solar cell modules. In comparison, GaAs has a larger optical absorption coefficient and nearly ideal band gap $\left(E_{\mathrm{g}}=1.45 \mathrm{eV}\right)$, although it still suffers from high surface recombination velocities. Colombo et al. have reported radial $\mathrm{p}-\mathrm{i}-\mathrm{n}$ diode NW solar cell devices based on GaAs that achieve efficiencies as high as $4.5 \%$ [30]. The enabled device based on a single NW-reported in this work had $\eta \sim 4.5 \%$ and $\mathrm{FF} \sim 0.65$ under AM $1.5 \mathrm{G}$ illumination. In parallel, LaPierre et al. fabricated GaAs radial $\mathrm{p}-\mathrm{n}$ NWs with the single NW devices exhibiting $\eta \sim 0.8 \%$ with $\mathrm{FF} \sim 0.26$ [21].

In addition to $\mathrm{Si}$ and GaAs NW solar cells, vertical p-GaN NPL arrays, epitaxially grown on n-type Si substrate have also been studied as heterostructured PV cells [32]. This type of device shows a welldefined rectifying behavior with low dark reverse bias current. The cell has $I_{\mathrm{sc}} \sim 7.6 \mathrm{~mA} \cdot \mathrm{cm}^{-2}$ and $\eta \sim 2.7 \%$ under AM 1.5 G illumination. Although this device structure does not have the advantage of carrier collection enhancement as for core/shell NPLs, the structure still demonstrated decreased reflectance.

\section{$1.3 \mathrm{CdS} / \mathrm{CdTe}$ NPL solar cell}

Recently, Fan et al. demonstrated a promising NPLbased solar cell module based on the CdS/CdTe system [20]. In this work, template assisted growth of highly ordered NPL arrays was demonstrated on aluminum foils without the need for epitaxial growth, which is often a cost limiting step involving a crystalline growth substrate. Additionally, as mentioned before, the use of the CdS/CdTe system with a relatively low surface recombination velocity of $10^{3}-10^{4} \mathrm{~cm} \cdot \mathrm{s}^{-1}[56,57]$ serves as an ideal platform for taking advantage of the high surface/junction area associated with NPL/NW structures.

The cells fabricated in this work consisted of single-crystalline n-type CdS NPLs embedded in a polycrystalline p-type CdTe thin film [20]. The CdTe film is primarily responsible for light absorption due to its direct band gap of $\sim 1.5 \mathrm{eV}$, close to the optimum band gap for PVs [38]. The radial built-in electric field at the interface of the two materials provides efficient photocarrier separation [39, 48]. The NPL solar cell structure takes full advantage of the orthogonal relationship between photon absorption and carrier collection previously discussed [39]. This structure relieves the competition between absorption and carrier collection and opens the design space. The net result is the ability to fabricate relatively efficient thin film solar devices with low quality optical materials thus potentially achieving cost competitive solar cells.

Template assisted, VLS growth of the CdS NPLs used in this work utilized porous anodic aluminum membranes [20]. A schematic diagram of the fabrication process is illustrated in Fig. 6. Briefly, a $\sim 2 \mu \mathrm{m}$ thick alumina film was grown on $0.25 \mathrm{~mm}$ thick aluminum foil by anodization in phosphoric acid solution at low temperature. Highly ordered pores in the alumina membrane formed a hexagonal array with $490 \mathrm{~nm}$ pitch and $200 \mathrm{~nm}$ diameter (Fig. 7(a)). The ordering was achieved by a combination of a preanodization nanoimprint on aluminum and matching the nanoimprint pitch with proper anodization voltage $[20,89]$. The well-known alumina barrier layer between the bottom of the pores and the underlying aluminum was thinned down to a few 


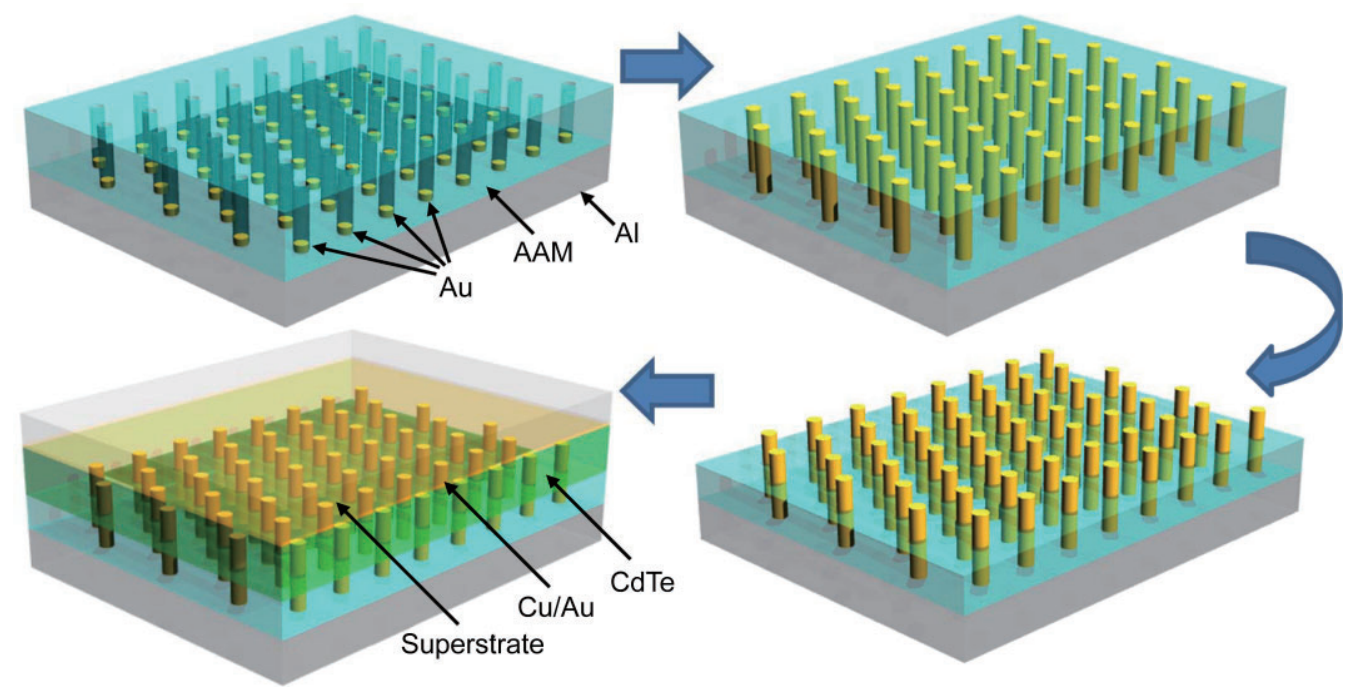

Figure 6 CdS NPLs/CdTe thin film cell fabrication scheme: (a) anodic alumina membrane (AAM) is grown on aluminum foil to form an array of pores in which Au catalyst is electrochemically deposited at the bottom; (b) template-assisted VLS growth of CdS NPLS is then applied; (c) AAM is partially etched to expose the top of the NPLs; (d) thin film of CdTe is deposited on the exposed NPL array by CVD, followed by thermal evaporation of $\mathrm{Cu} / \mathrm{Au}$ top contact. Reprinted with permission from Ref. [20] (Copyright 2009 Macmillan Publishers Ltd.)

nanometers [20, 90, 91]. Thinning the barrier allowed the electrodeposition of a thin Au layer $(\sim 300 \mathrm{~nm}$ thick) selectively at the bottom of the pores [20]. The CdS NPLs were then grown in the pores by a $\mathrm{Au}-$ catalyzed VLS process. After ion-milling to planarize the sample surface, the alumina membrane was selectively and partially etched in $1 \mathrm{~mol} / \mathrm{L} \mathrm{NaOH}$ to expose the NPL (Fig. 7(b)). The NPL exposed depth was systematically tuned by adjusting the $\mathrm{NaOH}$ etch time. A 1 $\mu$ m thick CdTe film was deposited on top of the exposed NPL arrays by chemical vapor deposition. $\mathrm{Cu} / \mathrm{Au}$ was thermally evaporated to form an ohmic top contact with the p-type CdTe film. The metal films were deposited only $14 \mathrm{~nm}$ thick in order to achieve acceptable transparency. Finally, the entire device was bonded on the top to a glass slide by epoxy for encapsulation. One of the key merits of this process scheme is the ability to fabricate high quality single crystalline semiconductors non-epitaxially on non-crystalline substrates. The as-grown CdS NPLs are single-crystalline as depicted by transmission electron microscopy shown in Figs. 7(c) and 7(d). Also, visible in Fig. 7(e) is the abrupt junction interface between the CdS NPLs and the CdTe film.

A photograph of a fully fabricated device with an active area of $\sim 5 \mathrm{~mm} \times 8 \mathrm{~mm}$ is shown in Fig. 8(a). The $I-V$ curves acquired under variable illumination
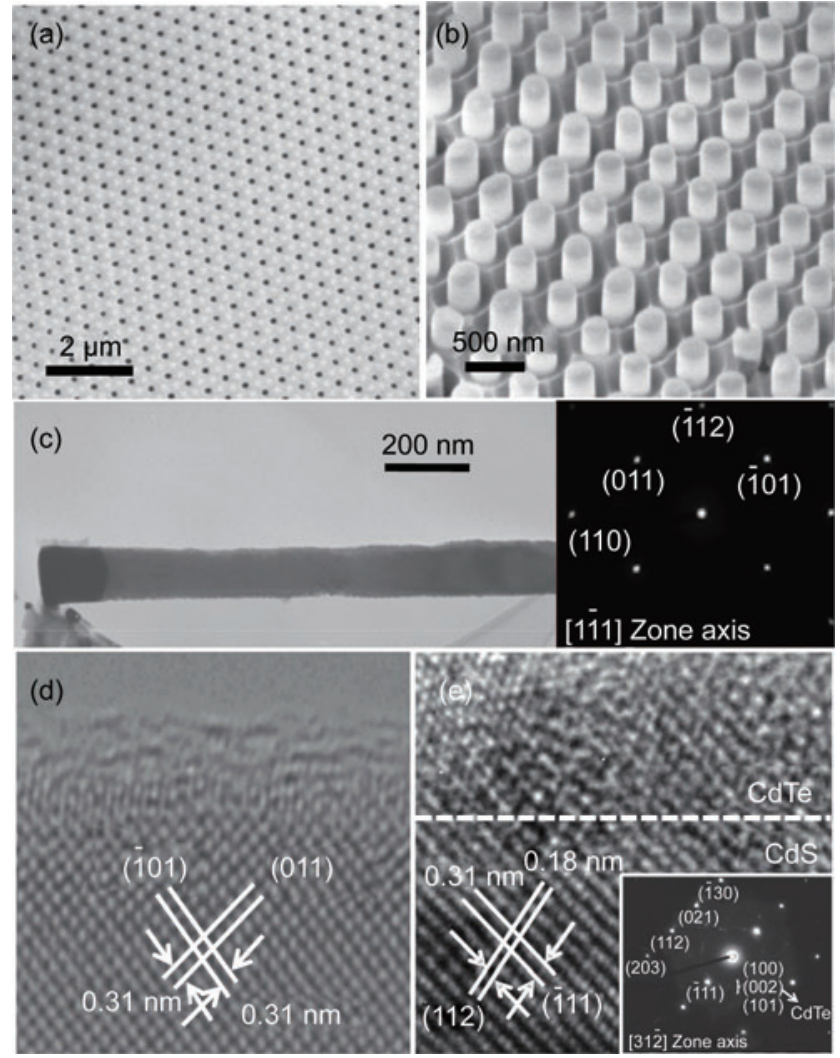

Figure 7 Characterization of CdS NPLs: (a) SEM image of highly ordered alumina pores used as the template for the VLS growth of CdS NPLs; (b) SEM image of partially exposed CdS NPLS in AAM; (c), (d) transmission electron microscopy (TEM) images verifying the single crystallinity of the CdS NPLs; (e) TEM depicting abrupt junction at the CdS NPL/CdTe thin film interface. Reprinted with permission from Ref. [20] (Copyright 2009 Macmillan Publishers Ltd.) 
intensity by using a solar simulator for the device are provided in Fig. 8(b). Under AM $1.5 \mathrm{G}\left(100 \mathrm{~mW} \cdot \mathrm{cm}^{-2}\right)$ illumination, values of $J_{\mathrm{sc}} \sim 21 \mathrm{~mA} \cdot \mathrm{cm}^{-2}, V_{\mathrm{oc}} \sim 0.62 \mathrm{~V}$, and $\mathrm{FF} 0.43$ were obtained. The conversion efficiency was $\sim 6 \%$, as shown in Fig. 8(c), mainly limited by the poor transmission of the metal contact and the absence of an antireflection coating [20]. Specifically, the top $\mathrm{Cu} / \mathrm{Au}$ metal contact had an optical transparency of only $50 \%$ which can be readily improved in the future, for instance, by the use of transparent metal oxide contacts. One of the key advantages with the 3-D NPL structure rests in the improved carrier collection efficiency which relies greatly on the geometric parameters, e.g., NPL embedded height $(H)$ in CdTe film. In this work, devices with variable $H$ were fabricated and characterized while maintaining the same overall CdTe thickness. As demonstrated in Fig. 8(d), energy conversion efficiency monotonically increases from $\sim 0.4 \%$ for $H=0 \mathrm{~nm}$ to $\sim 6 \%$ for

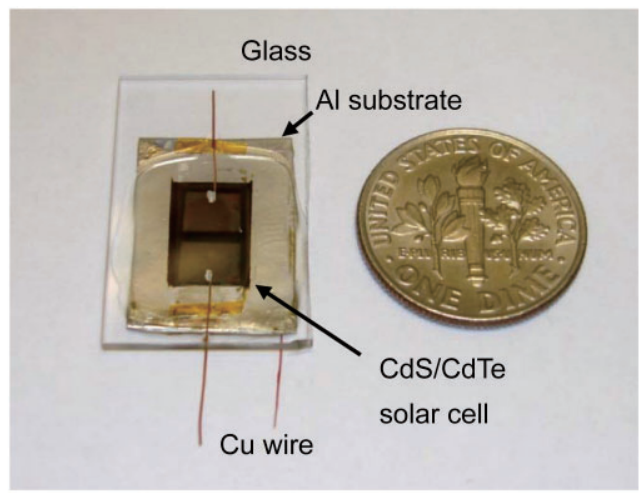

(a)

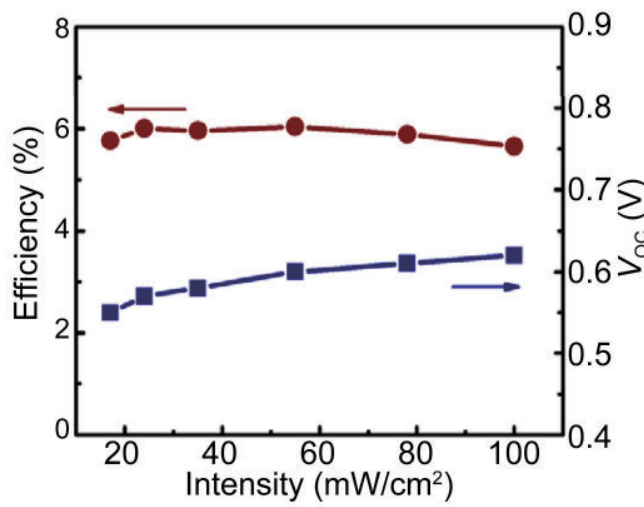

(c)
$H=640 \mathrm{~nm}$. When $H=0 \mathrm{~nm}$, only the top surface of the CdS NPLs is in contact with the CdTe film resulting in a small space charge region with low carrier collection efficiency. Thus, the majority of the photogenerated carriers recombine in the CdTe film via a nonradiative mechanism before being collected [20]. However, with increased $H$, the space charge region is significantly enlarged with much improved carrier collection efficiency, leading to much improved conversion efficiency. These results clearly demonstrate the benefit of the 3-D structure for a material system with relatively low surface recombination velocity, and suggest a future direction to enhance device performance by optimizing the geometric design of the device structure.

Besides the benefit of energy conversion efficiency, this work also demonstrated the excellent versatility in the fabrication and ultimate application of the NPL solar cell by integrating the device onto a flexible

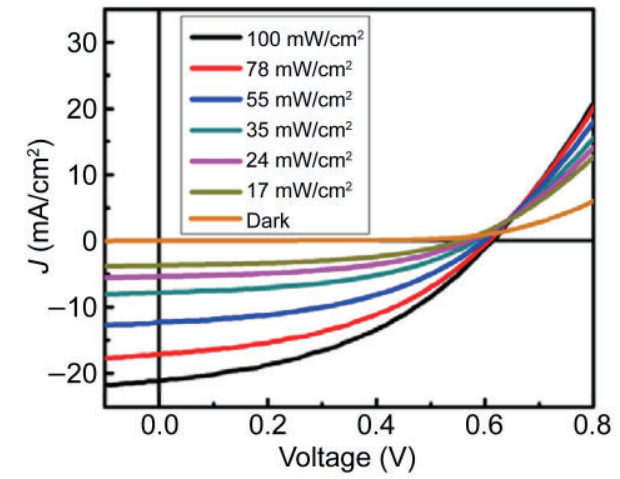

(b)

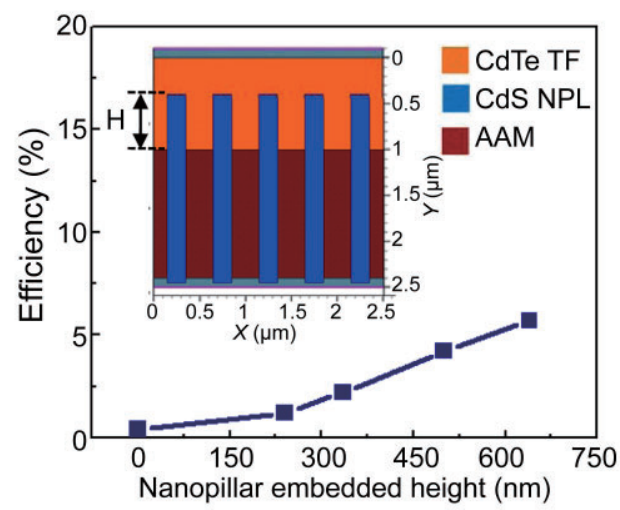

(d)

Figure 8 CdS NPL/CdTe thin film PVs: (a) an optical image of a fully fabricated cell bonded to a glass substrate; (b) $I-V$ characteristics under various illumination conditions; (c) conversion efficiency, $\eta$, and open circuit voltage, $V_{o c}$ as a function of illumination intensity; (d) efficiency as a function of the embedded NPL height, $H$. The CdTe film thickness is maintained constant at $\sim 1 \mu \mathrm{m}$. Reprinted with permission from Ref. [20] (Copyright 2009 Macmillan Publishers Ltd.) 
substrate [20]. To achieve this, the device was bonded to a piece of flexible polydimethylsiloxane (PDMS) substrate instead of a glass substrate. The aluminum back substrate was then completely removed by a wet chemical etch. $200 \mathrm{~nm}$ of indium was deposited to contact the CdS NPLs prior to a second piece of PDMS being bonded to the back side to complete the flexible encapsulation. Figure 9(a) shows a schematic of this flexible solar structure with the optical image of a fully fabricated device shown in Fig. 9(b). Mechanical bending of this module results in limited strain on the active elements as the NPLs are in the neutral mechanical plane of the substrate. From finite element simulations, the NPLs experience a maximum of only $\sim 0.01 \%$ strain for a $3-\mathrm{cm}$ radius of curvature [20]. The $I-V$ curves measured at different bending radii show negligible change upon bending, even for small radius of $2.7 \mathrm{~cm}$ (Fig. 9(c)), proving the versatility of the module for flexible PV applications.

\section{Conclusions}

In summary, significant progress has been made in understanding and fabricating a wide range of NW/NPL solar cells with the highest device conversion efficiency of $\sim 6 \%$ and materials conversion efficiency of $\sim 12 \%$ (the difference corresponds to the $\sim 50 \%$ optically transparent top contacts utilized in the work) [20]. The geometry of NPLs provides a unique opportunity for fabricating novel device structures with tunable optical absorption and carrier collection properties. For instance, by exploring radial junctions, orthogonalization of the light absorption and carrier collection processes is achieved which can significantly enhance the carrier collection efficiencies. Additionally, the 3-D geometric configuration of NPLs results in reduced optical reflectance and therefore enhanced absorption. The geometry of the NPL cells with high surface/interface area, however, presents major constraints. Mainly, the choice of the material system is critical. NPL cells only provide an advantage when the surface recombination rates are lower than the bulk recombination rates. This suggest that $\mathrm{Si}$ and GaAs material systems which are known to have high surface recombination velocities

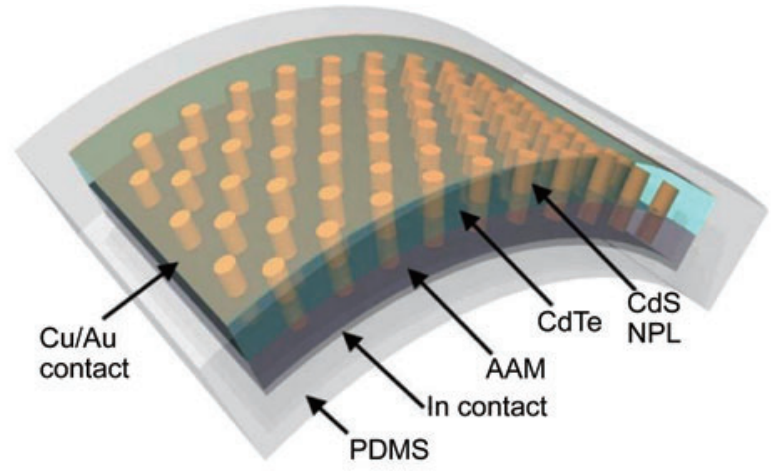

(a)

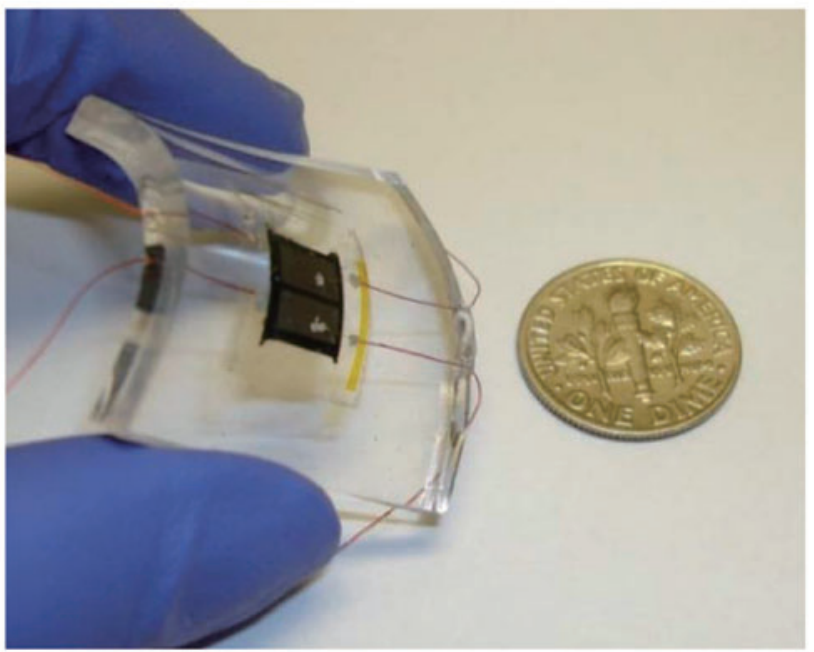

(b)

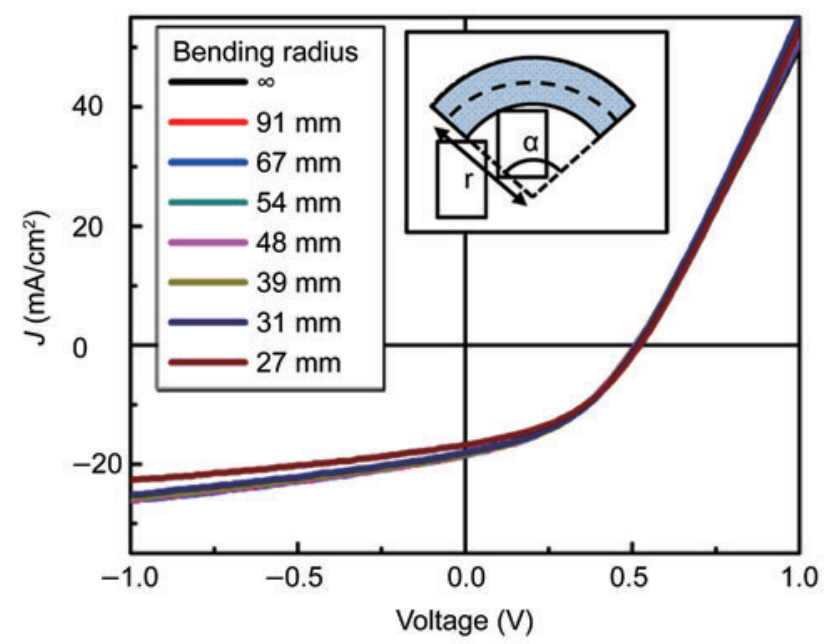

(c)

Figure 9 Mechanically flexible CdS NPLs/CdTe thin film PVs: (a) schematic and (b) optical image of a bendable module embedded in PDMS; (c) $I-V$ characteristics of a flexible cell for various bending radii, showing minimal dependence on curvature. Reprinted with permission from Ref. [20] (Copyright 2009 Macmillan Publishers Ltd.) 
may not be ideal material platforms for NPL PVs as evident from the results published in the literature, although appropriate surface treatment may in the future enhance the device performances. On the other hand, certain II-VI material systems, such as $\mathrm{CdS} / \mathrm{CdTe}$ with low surface recombination velocities may present a more desirable material system for exploring 3-D NPL cells. In that regard, detailed characterization of the carrier dynamics and the role of surface/interface states for various NPL materials are needed to further understand the intrinsic properties and potential efficiencies of the enabled cells. Additionally, the doping concentrations have to be further optimized and carefully characterized. In the future, optimization of NPL geometry, material system, and surface treatments will be essential in order to fully exploit the novel properties of these structures for PV applications.

\section{References}

[1] Lu, W.; Lieber, C. M. Nanoelectronics from the bottom up. Nat. Mater. 2007, 6, 841-850.

[2] Javey, A.; Nam, S.; Friedman, R. S.; Yan, H.; Lieber, C. $M$. Layer-by-layer assembly of nanowires for threedimensional, multifunctional electronics. Nano Lett. 2007, 7, 773-777.

[3] Xiang, J.; Lu, W.; Hu, Y. J.; Wu, Y.; Yan, H.; Lieber, C. M. $\mathrm{Ge} / \mathrm{Si}$ nanowire heterostructures as high-performance field-effect transistors. Nature 2006, 441, 489-493.

[4] Wang, D.; Dai, H. Germanium nanowires: From synthesis, surface chemistry, and assembly to devices. Appl. Phys.

A-Mater. 2006, 85, 217-225.

[5] Javey, A. The 2008 Kavli Prize in Nanoscience: Carbon nanotubes. ACS Nano 2008, 2, 1329-1335.

[6] Thelander, C.; Rehnstedt, C.; Froberg, L. E.; Lind, E.; Martensson, T.; Caroff, P.; Lowgren, T.; Ohlsson, B. J.; Samuelson, L.; Wernersson, L. E. Development of a vertical wrap-gated InAs FET. IEEE T. Electron Dev. 2008, 11, 3030-3036.

[7] Ford, A. C.; Ho, J. C.; Chueh, Y. L.; Tseng, Y. C.; Fan, Z. Y.; Guo, J.; Bokor, J.; Javey, A. Diameter-dependent electron mobility of InAs nanowires. Nano Lett. 2009, 9, 360365.

[8] Zhong, Z. H.; Qian, F.; Wang, D. L.; Lieber, C. M. Synthesis of $p$-type gallium nitride nanowires for electronic and photonic nanodevices. Nano Lett. 2003, 3 , 343-346.

[9] Qian, F.; Gradecak, S.; Li, Y.; Wen, C. Y.; Lieber, C. M. Core/multishell nanowire heterostructures as multicolor, high-efficiency light-emitting diodes. Nano Lett. 2005, 5, 2287-2291.

[10] Fan, Z. Y.; Chang, P. C.; Lu, J. G.; Walter, E. C.; Penner, R. M.; Lin, C. H.; Lee, H. P. Photoluminescence and polarized photodetection of single $\mathrm{ZnO}$ nanowires. Appl. Phys. Lett. 2004, 85, 6128-6130.

[11] Fan, Z. Y.; Wang, D. W.; Chang, P. C.; Tseng, W. Y.; Lu, J. G. ZnO nanowire field-effect transistor and oxygen sensing property. Appl. Phys. Lett. 2004, 85, 5923-5925.

[12] Fan, Z. Y.; Lu, J. G. Gate-refreshable nanowire chemical sensors. Appl. Phys. Lett. 2005, 86, 123510.

[13] Hahm, J.; Lieber, C. M. Direct ultrasensitive electrical detection of DNA and DNA sequence variations using nanowire nanosensors. Nano Lett. 2004, 4, 51-54.

[14] Zhang, D. H.; Liu, Z. Q.; Li, C.; Tang, T.; Liu, X. L.; Han, S.; Lei, B.; Zhou, C. W. Detection of $\mathrm{NO}_{2}$ down to ppb levels using individual and multiple $\mathrm{In}_{2} \mathrm{O}_{3}$ nanowire devices. Nano Lett. 2004, 4, 1919-1924.

[15] Fan, Z. Y.; Ho, J. C.; Jacobson, Z. A.; Razavi, H.; Javey, A. Large-scale, heterogeneous integration of nanowire arrays for image sensor circuitry. Proc. Natl. Acad. Sci. U.S.A. 2008, 105, 11066-11070.

[16] Chen, P.; Shen, G.; Zhou, C. Chemical sensors and electronic noses based on 1-D metal oxide nanostructures. IEEE T. Nanotechnol. 2008, 7, 668-682.

[17] Hochbaum, A. I.; Chen, R. K.; Delgado, R. D.; Liang, W. J.; Garnett, E. C.; Najarian, M.; Majumdar, A.; Yang, P. D. Enhanced thermoelectric performance of rough silicon nanowires. Nature 2008, 451, 163-167.

[18] Yan, Q.; Cheng, H.; Zhou, W.; Hng, H. H.; Yin, F.; Boey, F. Y. C.; Ma, J. A simple chemical approach for PbTe nanowires with enhanced thermoelectric properties. Chem. Mat. 2008, 20, 6298-6300.

[19] Wang, Z. L.; Song, J. H. Piezoelectric nanogenerators based on zinc oxide nanowire arrays. Science 2006, 312, 242-246.

[20] Fan, Z. Y.; Razavi, H.; Do, J. W.; Moriwaki, A.; Ergen, O.; Chueh, Y. L.; Leu, P. W.; Ho, J. C.; Takahashi, T.; Reichertz, L. A.; Neale, S.; Yu, K.; Wu, M.; Ager, J. W.; Javey, A. Three-dimensional nanopillar-array photovoltaics on lowcost and flexible substrates. Nat. Mater. 2009, 8, 648653. 
[21] Czaban, J. A.; Thompson, D. A.; LaPierre, R. R. GaAs core-shell nanowires for photovoltaic applications. Nano Lett. 2009, 9, 148-154.

[22] Garnett, E. C.; Yang, P. D. Silicon nanowire radial p-n junction solar cells. J. Am. Chem. Soc. 2008, 130, 92249225.

[23] Kelzenberg, M. D.; Turner-Evans, D. B.; Kayes, B. M.; Filler, M. A.; Putnam, M. C.; Lewis, N. S.; Atwater, H. A. Photovoltaic measurements in single-nanowire silicon solar cells. Nano Lett. 2008, 8, 710-714.

[24] Martinson, A. B. F.; Elam, J. W.; Liu, J.; Pellin, M. J.; Marks, T. J.; Hupp, J. T. Radial electron collection in dyesensitized solar cells. Nano Lett. 2008, 8, 2862-2866.

[25] Stelzner, T.; Pietsch, M.; Andra, G.; Falk, F.; Ose, E.; Christiansen, S. Silicon nanowire-based solar cells. Nanotechnology 2008, 19, 295203.

[26] Tian, B. Z.; Zheng, X. L.; Kempa, T. J.; Fang, Y.; Yu, N. F.; Yu, G. H.; Huang, J. L.; Lieber, C. M. Coaxial silicon nanowires as solar cells and nanoelectronic power sources. Nature 2007, 885-889.

[27] Tsakalakos, L.; Balch, J.; Fronheiser, J.; Korevaar, B. A.; Sulima, O.; Rand, J. Silicon nanowire solar cells. Appl. Phys. Lett. 2007, 91, 233117.

[28] Law, M.; Greene, L. E.; Johnson, J. C.; Saykally, R.; Yang, P. D. Nanowire dye-sensitized solar cells. Nat. Mater. 2005, 4, 455-459.

[29] Song, M. Y.; Ahn, Y. R.; Jo, S. M.; Kim, D. Y.; Ahn, J. P. $\mathrm{TiO}_{2}$ single-crystalline nanorod electrode for quasi-solidstate dye-sensitized solar cells. Appl. Phys. Lett. 2005, 87, 113113

[30] Colombo, C.; Heiss, M.; Gratzel, M.; Morral, A. F. I. Gallium arsenide $\mathrm{p}-\mathrm{i}-\mathrm{n}$ radial structures for photovoltaic applications. Appl. Phys. Lett. 2009, 94, 173108.

[31] Kempa, T. J.; Tian, B.; Kim, D. R.; Hu, J.; Zheng, X.; Lieber, C. M. Single and tandem axial $p-i-n$ nanowire photovoltaic devices. Nano Lett. 2008, 8, 3456-3460

[32] Tang, Y. B.; Chen, Z. H.; Song, H. S.; Lee, C. S.; Cong, H. T.; Cheng, H. M.; Zhang, W. J.; Bello, I.; Lee, S. T. Vertically aligned p-type single-crystalline GaN nanorod arrays on n-type Si for heterojunction photovoltaic cells. Nano Lett. 2008, 8, 4191-4195.

[33] Greene, L. E.; Law, M.; Yuhas, B. D.; Yang, P. D. ZnO$\mathrm{TiO}_{2}$ core-shell nanorod/P3HT solar cells. J. Phys. Chem. C 2007, 111, 18451-18456.

[34] Peng, K. Q.; Xu, Y.; Wu, Y.; Yan, Y. J.; Lee, S. T.; Zhu, J. Aligned single-crystalline Si nanowire arrays for photovoltaic applications. Small 2005, 1, 1062-1067.

[35] Muskens, O. L.; Rivas, J. G.; Algra, R. E.; Bakkers, E. P. A. M.; Lagendijk, A. Design of light scattering in nanowire materials for photovoltaic applications. Nano Lett. 2008, 8, 2638-2642.

[36] Zhu, J.; Yu, Z. F.; Burkhard, G. F.; Hsu, C. M.; Connor, S. T.; Xu, Y. Q.; Wang, Q.; McGehee, M.; Fan, S. H.; Cui, Y. Optical absorption enhancement in amorphous silicon nanowire and nanocone arrays. Nano Lett. 2009, 9, 279 282.

[37] Stiebig, H.; Senoussaoui, N.; Zahren, C.; Haase, C.; Muller, J. Silicon thin-film solar cells with rectangularshaped grating couplers. Prog. Photovoltaics 2006, 14, 13-24.

[38] Fahrenbruch, A. L.; Bube, R. H. In Fundamentals of Solar Cells: Photovoltaic Solar Energy Conversion. Academic Press: New York, 1983.

[39] Kayes, B. M.; Atwater, H. A.; Lewis, N. S. Comparison of the device physics principles of planar and radial $p-n$ junction nanorod solar cells. J. Appl. Phys. 2005, 97, 114302

[40] Kosyachenko, L. A.; Savchuk, A. I.; Grushko, E. V. Dependence of efficiency of thin-film CdS/CdTe solar cell on parameters of absorber layer and barrier structure. Thin Solid Films 2009, 517, 2386-2391.

[41] van Nieuwenhuysen, K.; Duerinckx, F.; Kuzma, I.; Payo, M. R.; Beaucarne, G.; Poortmans, J. Epitaxially grown emitters for thin film crystalline silicon solar cells. Thin Solid Films 2008, 517, 383-384.

[42] Marsillac, S.; Parikh, V. Y.; Compaan, A. D. Ultra-thin bifacial CdTe solar cell. Sol. Energ. Mat. Sol. C. 2007, 91, 1398-1402.

[43] Romeo, A.; Khrypunov, G.; Galassini, S.; Zogg, H.; Tiwari, A. N. Bifacial configurations for CdTe solar cells. Sol. Energ. Mat. Sol. C. 2007, 91, 1388-1391.

[44] Beaucarne, G.; Duerinckx, F.; Kuzma, I.; van Nieuwenhuysen, K.; Kim, H. J.; Poortmans, J. Epitaxial thin-film Si solar cells. Thin Solid Films 2006, 533-542.

[45] Schermer, J. J.; Mulder, P.; Bauhuis, G. J.; Larsen, P. K.; Oomen, G.; Bongers, E. Thin-film GaAs epitaxial lifeoff solar cells for space applications. Prog. Photovoltaics 2005, 13, 587-596.

[46] Bridge, C. J.; Dawson, P.; Buckle, P. D.; Ozsan,M. E. Photoluminescence spectroscopy and decay time measurements of polycrystalline thin film CdTe. J. Appl. Phys. 2000, 88, 6451-6456. 
[47] Gunawan, O.; Guha, S. Characteristics of vapor-liquidsolid grown silicon nanowire solar cells. Sol. Energ. Mat. Sol. C. 2009, 93, 1388-1393.

[48] Anandan, S.; Wen, X. G.; Yang, S. H. Room temperature growth of CuO nanorod arrays on copper and their application as a cathode in dye-sensitized solar cells. Mater. Chem. Phys. 2005, 93, 35-40.

[49] Jiu, J. T.; Wang, F. M.; Isoda, S.; Adachi, M. Highly efficient dye-sensitized solar cells based on single crystalline $\mathrm{TiO}_{2}$ nanorod film. Chem. Lett. 2005, 34, 1506-1507.

[50] Adachi, M.; Murata, Y.; Takao, J.; Jiu, J. T.; Sakamoto, M.; Wang, F. M. Highly efficient dyesensitized solar cells with a titania thin-film electrode composed of a network structure of singlecrystal-like $\mathrm{TiO}_{2}$ nanowires made by the "oriented attachment" mechanism. J. Am. Chem. Soc. 2004, 126, 14943-14949.

[51] Sharma, A. K.; Agarwal, S. K.; Singh, S. N. Determination of front surface recombination velocity of silicon solar cells using the short-wavelength spectral response. Sol. Energ. Mat. Sol. C. 2007, 91, 1515-1520.

[52] Sabbah, A. J.; Riffe, D. M. Measurement of silicon surface recombination velocity using ultrafast pumpprobe reflectivity in the near infrared. J. Appl. Phys. 2000, 88, 6954-6956.

[53] Rowe, M. W.; Liu, H. L.; Williams, G. P.; Williams, R. T. Picosecond photoelectron-spectroscopy of excited-states at $\mathrm{Si}(111) \sqrt{3} \times \sqrt{3} R 30^{\circ}-\mathrm{B}, \mathrm{Si}(111) 7 \times 7, \mathrm{Si}(100) 2 \times 1$, and laser-annealed Si(111)1×1 surfaces. Phys. Rev. B 1993, 47, 2048-2064.

[54] Passlack, M.; Hong, M.; Mannaerts, J. P.; Kwo, J. R.; Tu, L. W. Recombination velocity at oxide-GaAs interfaces fabricated by in situ molecular beam epitaxy. Appl. Phys. Lett. 1996, 68, 3605-3607.

[55] Jastrzebski, L.; Lagowski, J.; Gatos, H. C. Application of scanning electron-microscopy to determination of surface recombination velocity: GaAs. Appl. Phys. Lett. 1975, 27, 537-539.

[56] Rosenwaks, Y.; Burstein, L.; Shapira, Y.; Huppert, D. Effects of reactive versus unreactive metals on the surface recombination velocity at $\mathrm{Cds}$ and $\mathrm{CdSe}(1120)$ interfaces. Appl. Phys. Lett. 1990, 57, 458-460.

[57] Delgadillo, I.; Vargas, M.; CruzOrea, A.; AlvaradoGil, J. J.; Baquero, R.; SanchezSinencio, F.; Vargas, H. Photoacoustic CdTe surface characterization. Appl. Phys. B-Lasers O. 1997, 64, 97-101.
[58] Gottschalch, V.; Wagner, G.; Bauer, J.; Paetzelt, H.; Shirnow, M. VLS growth of GaN nanowires on various substrates. J. Cryst. Growth 2008, 310, 5123-5128.

[59] Chen, Y. Q.; Cui, X. F.; Zhang, K.; Pan, D. Y.; Zhang, S. Y.; Wang, B.; Hou, J. G. Bulk-quantity synthesis and self-catalytic VLS growth of $\mathrm{SnO}_{2}$ nanowires by lowertemperature evaporation. Chem. Phys. Lett. 2003, 369, 16-20.

[60] Zhang, X.; Lew, K.; Nimmatoori, P.; Redwing, J. M.; Dickey, E. C. Diameter-dependent composition of vaporliquid-solid grown $\mathrm{Si}_{1-x} \mathrm{Ge}_{x}$ nanowires. Nano Lett. 2007, 7, 3241-3245.

[61] Li, S. Y.; Lin, P.; Lee, C. Y.; Tseng, T. Y. Field emission and photofluorescent characteristics of zinc oxide nanowires synthesized by a metal catalyzed vapor-liquid-solid process. J. Appl. Phys. 2004, 95, 3711-3716.

[62] Wu, Y. Y.; Yang, P. D. Direct observation of vapor-liquidsolid nanowire growth. J. Am. Chem. Soc. 2001, 123, 3165-3166.

[63] Lauhon, L. J.; Gudiksen, M. S.; Lieber, C. M. Semiconductor nanowire heterostructures. Philos. T. $R$. Soc. A 2004, 362, 1247-1260.

[64] Lauhon, L. J.; Gudiksen, M. S.; Wang, C. L.; Lieber, C. M. Epitaxial core-shell and coremultishell nanowire heterostructures. Nature 2002, 420, 57-61.

[65] Durgun, E.; Akman, N.; Ataca, C.; Ciraci, S. Atomic and electronic structures of doped silicon nanowires: A firstprinciples study. Phys. Rev. B 2007, 76, 245323.

[66] Nazeeruddin, M. K.; Pechy, P.; Renouard, T.; Zakeeruddin, S. M.; Humphry-Baker, R.; Comte, P.; Liska, P.; Cevey, L.; Costa, E.; Shklover, V.; Spiccia, L.; Deacon, G. B.; Bignozzi, C. A.; Gratzel, M. Engineering of efficient panchromatic sensitizers for nanocrystalline $\mathrm{TiO}_{2}$-based solar cells. J. Am. Chem. Soc. 2001, 123, 1613-1624.

[67] Wang, P.; Zakeeruddin, S. M.; Moser, J. E.; Nazeeruddin, M. K.; Sekiguchii, T.; Gratzel, M. A stable quasi-solidstate dye-sensitized solar cell with an amphiphilic ruthenium sensitizer and polymer gel electrolyte. Nat. Mater. 2003, 2, 402-407.

[68] Rensmo, H.; Keis, K.; Lindstrom, H.; Sodergren, S.; Solbrand, A.; Hagfeldt, A.; Lindquist, S. E.; Wang, L. N.; Muhammed, M. High light-to-energy conversion efficiencies for solar cells based on nanostructured $\mathrm{ZnO}$ electrodes. J. Phys. Chem. B 1997, 101, 2598-2601.

[69] Tennakone, K.; Kumara, G. R. R. A.; Kottegoda, I. R. M.; Perera, V. P. S. An efficient dyesensitized 
photoelectrochemical solar cell made from oxides of tin and zinc. Chem. Commun. 1999, 15-16.

[70] Keis, K.; Magnusson, E.; Lindstrom, H.; Lindquist, S. E.; Hagfeldt, A. A 5\% efficient photo electrochemical solar cell based on nanostructured $\mathrm{ZnO}$ electrodes. Sol. Energ. Mat. Sol. C. 2002, 73, 51-58.

[71] Gregg, B. A. Excitonic solar cells. J. Phys. Chem. B 2003, 107, 4688-4698.

[72] Hara, K.; Wang, Z. S.; Sato, T.; Furube, A.; Katoh, R.; Sugihara, H.; Dan-Oh, Y.; Kasada, C.; Shinpo, A.; Suga, S. Oligothiophene-containing coumarin dyes for efficient dye-sensitized solar cells. J. Phys. Chem. B 2005, 109, 15476-15482.

[73] Horiuchi, T.; Miura, H.; Sumioka, K.; Uchida, S. High efficiency of dye-sensitized solar cells based on metalfree indoline dyes. J .Am. Chem. Soc. 2004, 126, 12218 $-12219$.

[74] Altobello, S.; Argazzi, R.; Caramori, S.; Contado, C.; Da Fre, S.; Rubino, P.; Chone, C.; Larramona, G.; Bignozzi, C. A. Sensitization of nanocrystalline $\mathrm{TiO}_{2}$ with black absorbers based on Os and Ru polypyridine complexes. J. Am. Chem. Soc. 2005, 127, 15342-15343.

[75] Robertson, N. Optimizing dyes for dye-sensitized solar cells. Angew. Chem. Int. Edit. 2006, 45, 2338-2345.

[76] Zukalova, M.; Zukal, A.; Kavan, L.; Nazeeruddin, M. K.; Liska, P.; Gratzel, M. Organized mesoporous $\mathrm{TiO}_{2}$ films exhibiting greatly enhanced performance in dyesensitized solar cells. Nano Lett. 2005, 5, 1789-1792.

[77] Green, A. N. M.; Palomares, E.; Haque, S. A.; Kroon, J. M.; Durrant, J. R. Charge transport versus recombination in dye-sensitized solar cells employing nanocrystalline $\mathrm{TiO}_{2}$ and $\mathrm{SnO}_{2}$ films. J. Phys. Chem. B 2005, 109, 12525 -12533 .

[78] Fisher, A. C.; Peter, L. M.; Ponomarev, E. A.; Walker, A. B.; Wijayantha, K. G. U. Intensity dependence of the back reaction and transport of electrons in dye-sensitized nanacrystalline $\mathrm{TiO}_{2}$ solar cells. J. Phys. Chem. B 2000, 104, 949-958.

[79] Oekermann, T.; Zhang, D.; Yoshida, T.; Minoura, H. Electron transport and back reaction in nanocrystalline $\mathrm{TiO}_{2}$ films prepared by hydrothermal crystallization. J. Phys. Chem. B 2004, 108, 2227-2235.

[80] Nelson, J. Continuous-time random-walk model of electron transport in nanocrystalline $\mathrm{TiO}_{2}$ electrodes. Phys. Rev. B 1999, 59, 15374-15380.
[81] van de Lagemaat, J.; Frank, A. J. Nonthermalized electron transport in dye-sensitized nanocrystalline $\mathrm{TiO}_{2}$ films: Transient photocurrent and random-walk modeling studies. J. Phys. Chem. B 2001, 105, 11194-11205.

[82] Kopidakis, N.; Benkstein, K. D.; van de Lagemaat, J.; Frank, A. J. Transport-limited recombination of photocarriers in dye-sensitized nanocrystalline $\mathrm{TiO}_{2}$ solar cells. J. Phys. Chem. B 2003, 107, 11307-11315.

[83] Zaban, A.; Chen, S. G.; Chappel, S.; Gregg, B. A. Bilayer nanoporous electrodes for dye sensitized solar cells. Chem. Commun. 2000, 2231-2232.

[84] Tennakone, K.; Bandara, J.; Bandaranayake, P. K. M.; Kumara, G. R. A.; Konno, A. Enhanced efficiency of a dye-sensitized solar cell made from $\mathrm{MgO}$-coated nanocrystalline $\mathrm{SnO}_{2}$. Jpn. J. Appl. Phys. 2001, 40, L732L734.

[85] Palomares, E.; Clifford, J. N.; Haque, S. A.; Lutz,T.; Durrant, J. R. Control of charge recombination dynamics in dye sensitized solar cells by the use of conformally deposited metal oxide blocking layers. J. Am. Chem. Soc. 2003, 125, 475-482.

[86] Diamant, Y.; Chappel, S.; Chen, S. G.; Melamed, O.; Zaban, A. Core-shell nanoporous electrode for dye sensitized solar cells: The effect of shell characteristics on the electronic properties of the electrode. Coord. Chem. Rev. 2004, 248, 1271-1276.

[87] Bandaranayake, K. M. P.; Indika Senevirathna, M. K. I.; Prasad Weligamuwa, P. M. G. M. P.; Tennakone, K. Dyesensitized solar cells made from nanocrystalline $\mathrm{TiO}_{2}$ films coated with outer layers of different oxide materials. Coord. Chem. Rev. 2004, 248, 1277-1281.

[88] Law, M.; Greene, L. E.; Radenovic, A.; Kuykendall, T.; Liphardt, J.; Yang, P. D. ZnO- $\mathrm{Al}_{2} \mathrm{O}_{3}$ and $\mathrm{ZnO}-\mathrm{TiO}_{2}$ coreshell nanowire dye-sensitized solar cells. J. Phys. Chem. $B$ 2006, 110, 22652-22663.

[89] Mikulskas, I.; Juodkazis, S.; Tomasiunas, R.; Dumas, J. G. Aluminum oxide photonic crystals grown by a new hybrid method. Adv. Mater. 2001, 13, 1574-1577.

[90] Fan, Z. Y.; Dutta, D.; Chien, C. J.; Chen, H. Y.; Brown, E. C.; Chang, P. C.; Lu, J. G. Electrical and photoconductive properties of vertical $\mathrm{ZnO}$ nanowires in high density arrays. Appl. Phys. Lett. 2006, 89, 213110.

[91] Nielsch, K.; Muller, F.; Li, A. P.; Gosele, U. Uniform nickel deposition into ordered alumina pores by pulsed electrodeposition. Adv. Mater. 2000, 12, 582-586. 